\title{
Lithium safety and tolerability in mood disorders: a critical review
}

\section{Tolerabilidade e segurança do lítio em transtornos do humor: uma revisão crítica}

\author{
Ivan Aprahamian ${ }^{1}$, Rafael Teixeira de Sousa ${ }^{1}$, Leandro da Costa Lane Valiengo ${ }^{1}$, Rodrigo Machado-Vieira ${ }^{1,2}$, \\ ORESTES VicENTE ForLENZA ${ }^{1}$
}

1 Laboratory of Neuroscience (LIM-27), Department and Institute of Psychiatry, Faculty of Medicine, University of São Paulo (USP), Brazil.

2 Experimental Therapeutics and Pathophysiology Branch, National Institute of Mental Health (NIH), Bethesda, MD, EUA.

Received: $1 / 8 / 2014$ - Accepted: $1 / 14 / 2014$

\begin{abstract}
Background: Lithium is a first-line treatment for bipolar disorder in all phases, also indicated as add-on drug for unipolar depression and suicide prevention. This study encompasses a broad critical review on the safety and tolerability of lithium for mood disorders. Methods: A computerized search for English written human studies was made in MEDLINE, using the keywords "lithium" and "mood disorders", starting from July 1993 through July 2013 (n = 416). This initial search aimed to select clinical trials, prospective data, and controlled design studies of lithium treatment for mood disorders reporting adverse effects ( $\mathrm{n}=$ 36). The final selection yielded 91 studies. Results: The most common general side effects in patients on lithium treatment were thirst, frequent urination, dry mouth, weight gain, fatigue and cognitive complaints. Lithium users showed a high prevalence of hypothyroidism, hyperparathyroidism, and decrease in urinary concentration ability. Reduction of glomerular filtration rate in patients using lithium was also observed, but in a lesser extent. The evidence of teratogenicity associated with lithium use is not well established. Anti-inflammatory non-steroidal drugs, thiazide diuretics, angiotensin-converting enzyme inhibitors, and alprazolam may increase serum lithium and the consequent risk for intoxication. Discussion: Short-term lithium treatment is associated with mild side effects. Medium and long-term lithium treatment, however, might have effects on target organs which may be prevented by periodical monitoring. Overall, lithium is still a safe option for the treatment of mood disorders.
\end{abstract}

Aprahamian I, et al. / Rev Psiq Clín. 2014;41(1):9-14

Keywords: Lithium, mood disorders, safety, tolerability.

\section{Resumo}

Contexto: O lítio é um tratamento de primeira linha para o transtorno bipolar, em todas as fases, e também é indicado como terapia adjunta para a depressão unipolar e prevenção do suicídio. Este estudo abrange uma ampla revisão crítica sobre a segurança e a tolerabilidade do lítio para transtornos do humor. Métodos: Uma busca informatizada para estudos com humanos escritos em inglês foi feita no MEDLINE, usando as palavras-chave "lítio" e "transtornos de humor", a partir de julho de 1993 a julho de 2013 ( $(n=416)$. Esta pesquisa inicial teve como objetivo selecionar ensaios clínicos, estudos prospectivos e estudos controlados com tratamento com lítio para transtornos de humor, relatando efeitos adversos $(n=36)$. A seleção final identificou 91 estudos. Resultados: Os efeitos colaterais mais comuns nos pacientes em tratamento com lítio foram sede, micção frequente, boca seca, ganho de peso, fadiga e queixas cognitivas. Usuários de lítio mostraram uma alta prevalência de hipotireoidismo, hiperparatireoidismo e diminuição da capacidade de concentração urinária. Também foi observada redução da taxa de filtração glomerular em pacientes utilizando lítio, mas em menor grau. A evidência de teratogenicidade associada com o uso de lítio não está bem estabelecida. Os medicamentos anti-inflamatórios não esteroides, diuréticos, inibidores da enzima de conversão da angiotensina e alprazolam podem aumentar o lítio sérico e o consequente risco de intoxicação. Conclusões: $O$ tratamento de curto prazo com lítio está associado com efeitos colaterais leves. No entanto, tratamentos de médio a longo prazo com lítio podem ter efeitos sobre órgãos-alvo que podem ser prevenidos por acompanhamento periódico. Em geral, o lítio é ainda uma alternativa segura para o tratamento dos transtornos de humor.

Aprahamian I, et al. / Rev Psiq Clín. 2014;41(1):9-14

Palavras-chave: Lítio; transtornos de humor; segurança; tolerância.

\section{Introduction}

Lithium represents an important therapeutic option in mood disorders, since its first clinical study by Mogens Schou in 19541. After almost 70 years of medical research, lithium salts have been shown effective for the protection against mania and depression, especially in the acute and long-term management of bipolar disorder ${ }^{2}$, and reducing both suicide and mortality in mood disorders ${ }^{3,4}$. More recently, new biological properties of lithium have been discovered, considering the drug for a pharmacological option for neurodegenerative and spinal cord disorders such as Alzheimer's disease ${ }^{5}$, amyotrophic lateral sclerosis ${ }^{6}$ and chronic spinal cord injuries 7.

Although most guidelines recommend the prescription of lithium as a first-line drug for the treatment of bipolar disorder8, but clinicians need to pay attention to its clinical safety profile. Lithium has as a narrow therapeutic window and the requirement for frequent lithium serum levels, as well as the evaluation of potentially disabling adverse effects (e.g. thirst, taste alteration, tremor, polyuria, weight gain), and the risk of teratogenicity, and the possibility of emergence of organic lesions (Table 1) with long-term use may limit its usefulness in some cases. In this context, renal dysfunction has been implicated as a major concern of physicians who prescribe lithium salts, due to their potential for developing renal impairment, even with heterogeneous and inconclusive available data and a prevalence for severe impairment of $1.2 \%{ }^{8-11}$.

Few studies have addressed the safety and tolerability of lithium in the clinical practice. First, the design of a randomized controlled trial studies in long-term (several years) maintenance is extremely expensive and with a high dropout rate. Also, lithium has alternatives to its prescription, although more costly, such as valproic acid and secondgeneration antipsychotics. These medications have beneficial actions very similar to lithium in the treatment of patients with mood disorders. 
Table 1. Most prevalent organ-damage related to lithium treatment

\begin{tabular}{|l|l|}
\hline \multicolumn{1}{|c|}{ Target organ/clinical status } & \multicolumn{1}{c|}{ Organic lesion } \\
\hline Kidneys & $\begin{array}{l}\text { Mild tubular dysfunction, diabetes } \\
\text { insipidus, nephrotic syndrome, } \\
\text { glomerular impairment }\end{array}$ \\
\hline Thyroid & $\begin{array}{l}\text { Subclinical/overt hypothyroidism, } \\
\text { autoimmune thyroiditis, } \\
\text { hyperthyroidism }\end{array}$ \\
\hline Parathyroid & Hyperthyroidism \\
\hline Skin & $\begin{array}{l}\text { Acne, folliculitis, maculopapular } \\
\text { eruptions, Psoriasis, alopecia }\end{array}$ \\
\hline Pregnancy & Teratogenecity (Ebstein's anomaly) \\
\hline
\end{tabular}

The aim of this study is to present a critical review on the safety and tolerability profiles of lithium treatment for patients with mood disorders.

\section{Methods}

This study encompasses a broad critical review on the safety and tolerability of lithium for mood disorders. A computerized search for English written human studies was made in MEDLINE, using the keywords 'lithium' and 'mood disorders', starting from July 1993 through July 2013. This initial search yielded 416 publications. A manual search especially evaluated clinical trials, prospective data, and controlled design studies involving lithium treatment for mood disorders $(n=36)$. In this search, our review dedicated a special interest on the last 10 years of evidence from randomized, placebocontrolled, double-blind and controlled trials reporting adverse effects. Other articles reporting safety and tolerability data not reported in prospective or controlled studies were selected, as well as review papers on this issue. A secondary complementary search over this data range was done specifically addressing the keywords "lithium" and "safety", "lithium" and "tolerability", "lithium" and "depression", and "lithium" and "bipolar disorder". Manual search from reference lists of the primary selected studies was also done. Three authors participated in the studies selection (I.A., R.T.S., and L.C.L.V.). We selected a total of 91 studies.

\section{Results}

\section{General aspects of commonly reported adverse effects}

Several symptomatic adverse effects are associated with the use of lithium, being the most common abdominal discomfort, diarrhea, tremor, polyuria, nocturia, weight gain, edema, and various forms of erythema ${ }^{12}$. Anorexia, nausea, vomiting, abdominal pain and diarrhea are particularly transient, occurring most often at the beginning of treatment ${ }^{13}$. From the overall of these symptoms, the most pronounced effects and with greater impact for the patients are thirst, frequent urination, dry mouth, weight gain, fatigue and cognitive disorders ${ }^{14}$. Some forms of rash may occur during therapy with lithium and it may exacerbate previously diagnosed psoriasis. In controlled trials, 15 to $20 \%$ of patients discontinue treatment because of adverse events and this percentage may rise in more naturalist conditions ${ }^{15,16}$. The prevalence of these adverse effects is higher than $20 \%$ during the long-term treatment directly related to the frequency and amount of the lithium salt administered ${ }^{9}$. However, the adhesion can be improved by providing accurate information about the drug, constant therapeutic supervision and psychological support ${ }^{17}$. The slow release formulations are associated with fewer adverse symptoms in clinical practice as previously described, especially regarding to digestive symptoms. In this latter, substitution of lithium carbonate by lithium citrate can occasionally improve this kind of complaint ${ }^{18}$.

Weight gain between 4 to 10 pounds is found in approximately $30 \%$ of patients 9,19 . However, in some studies, a gain above 20 pounds is not uncommon ${ }^{13}$. Generally, the weight increase appears to be related to lithium insulin-like properties in increasing cellular glucose uptake, increased thirst, direct stimulation of the hypothalamic appetite center, and the induction of clinical hypothyroidism. Although, no studies have explored the direct effect of lithium among users compared with control patients to evaluate possible specific influence with respect to weight gain. An experimental study with rats receiving low lithium levels, it was observed an increased serum levels of urea, glucose, and lipid peroxidase and reduced glutathione levels, indicating oxidative stress ${ }^{20}$. In this study, the histopathological examination of the tissues of the liver and kidneys showed various structural deformities and histological changes in rats treated with lithium. One possibility is the elevation of glucose reflects a change in pancreatic metabolism due to insulin deficiency. However, in another study with similar experimental design and histopathological findings, changes in glucose metabolism were not found ${ }^{21}$.

In the nervous system, the most common sign is the fine postural or action tremor, present in between 4 to $20 \%$ of cases $^{22}$. The tremor is more frequent and associated with the use of caffeine, antidepressants and neuroleptics, and potentially alleviated by concomitant use of betablockers $^{22}$. In regard to cognition, prolonged administration of lithium might produce discrete negative effects in learning, surveillance, alert and in short-term memory ${ }^{23,24}$. Patients also might report mental and psychomotor slowing after its use ${ }^{25}$. Generally, in clinical practice, the negative effects on cognition are commonly observed in memory, vigilance and reaction time ${ }^{23}$. In a placebo-controlled study involving functional magnetic resonance lithium has been shown to produce small but significant reduction in brain signals during oxygen-dependent cognitive tasks ${ }^{26}$. Exceptionally, electroencephalographic abnormalities, including non-convulsive status epilepticus, cerebellar changes and extrapyramidal signs may be present ${ }^{9}$.

\section{Thyroid and parathyroid disorders}

Thyroid dysfunction has been described during lithium therapy, especially among females ${ }^{27-29}$. It is currently recognized that the treatment can inhibit the production of thyroid hormones and induce clinical signs of hypothyroidism or hyperthyroidism, and even goiter. Lithium is concentrated inside the thyroid gland and has four potentially negative effects: inhibition of iodine uptake, inhibition of iodotyrosine coupling, alteration in thyroglobulin structure, and inhibition of thyroxine secretion ${ }^{30,31}$. The change in thyroid stimulating hormone or thyrotropin (TSH) is commonly common observed effect ${ }^{9}$. Lithium probably acts on the hypothalamus-pituitary axis resulting in an over-response of TSH release to thyrotropin-releasing hormone, as found in over $50 \%$ of patients in a previous study ${ }^{32}$. Both clinical and subclinical hypothyroidism showed a higher prevalence among lithium users ${ }^{33}$. The prevalence of clinical hypothyroidism was between 8 and 19\% among users of lithium compared with 0.5 to $1 \%$ in the general population ${ }^{33}$. Subclinical hypothyroidism presented a higher prevalence of $23 \%$ among lithium users compared to $10.3 \%$ from non-users ${ }^{33}$. In a study with 20 years of follow-up the incidence of hypothyroidism was 25/1000-year survivors ${ }^{34}$. A recent meta-analysis observed a six-fold increase of clinical hypothyroidism among patients receiving lithium therapy ${ }^{11}$.

There is a possible influence involving genetic, gender and clinical profile on hypothyroidism and lithium. In a prospective study, patients using lithium whose first-degree relatives had hypothyroidism presented the disease faster (3.7 versus 8.6 years) ${ }^{35}$. From a large retrospective study, female patients presented a $10 \%$ increase in prevalence of hypothyroidism when compared to men $(14 \% \text { versus } 4.5 \%)^{36}$. A prospective randomized study suggested that presence of hypothyroidism is associated with a lower response to the use of lithium ${ }^{37}$.

The incidence of thyroid goiter was present in $51 \%$ of 150 outpatients evaluated in a clinical observational study ${ }^{38}$. In this study, 19\% of subjects had subclinical hypothyroidism and $53 \%$ were positive for the presence of anti-thyroid antibodies, despite the absence of clinical cases of hypothyroidism, and positively correlated with age 
and time of lithium treatment. The decline in thyroid function may be associated with the presence or not of anti-thyroperoxidase ${ }^{32}$.

It is recommended that thyroid function be assessed by laboratory tests before the start, after 3 months and every 6 to 12 months during lithium therapy ${ }^{29}$. If the TSH is between 5 and $10 \mathrm{mU} / \mathrm{L}$, serum levels should be measured between 1 and 3 months. In case of levels above $10 \mathrm{mU} / \mathrm{L}$, it is recommended the introduction of levothyroxine independent of the presence of symptoms, intending to continue treatment with lithium ${ }^{33}$. Whether treatment of hypothyroidism in patients given lithium should follow this line of recommendation is unclear.

Although less prevalent, the hyperthyroidism can also occur during lithium treatment ${ }^{39}$. It was suggested that this dysfunction could be caused by an induction of an autoimmune thyroiditis or simply by exacerbation of a silent thyroiditis ${ }^{40}$. In a retrospective study of patients with hyperthyroidism, lithium exposure was associated with a 4.7 -fold higher risk for developing silent thyroiditis ${ }^{40}$.

Long-term lithium treatment also appears to be associated with the presence of hyperparathyroidism and hypercalcemia ${ }^{41}$. Even with normal or low levels of phosphate, $10-42 \%$ of patients develop some degree of serum hypercalcemia, and $29 \%$ are associated with elevated parathyroid hormone $(\mathrm{PTH})^{9}$. The mechanism although uncertain, is probably due to the inactivation of the calcium-sensing receptor and the interference with intracellular second messenger signaling, leading to a primary increased release of $\mathrm{PTH}$, with secondary raise of serum calcium ${ }^{42}$. In a retrospective study, total serum calcium was found to be higher than the reference value in $6 \%$ of patients; ionized calcium was higher in $25 \%$ and serum PTH in $23 \%{ }^{43}$.

In an epidemiological study, patients treated with lithium for more than 15 years presented 3 to 6 times more hypercalcemia compared with the general population ${ }^{44}$. In a prospective study, patients who had never previously used lithium had elevated PTH and increased calcium reabsorption along with reduced excretion of calcium, unlike that commonly observed with primary hyperparathyroidism ${ }^{45}$. Multiple case reports associated lithium use and hyperparathyroidism with single or multiple adenomas of the parathyroid glands ${ }^{42}$. A previous study observed that total calcium levels were significantly higher in the lithium-treated group compared to patients who were treated with other psychotropic agents ${ }^{35}$. Symptoms of hypercalcemia require suspension of lithium therapy immediately.

Current guidelines for bipolar disorder do not specify direct recommendations regarding serum monitoring of calcium and $\mathrm{PTH}^{46}$. Baseline blood tests before lithium prescription should include TSH, free tiroxine, PTH and calcium, and should be monitored every year or more frequently if any clinical suspicious of one of these disorders.

\section{Renal impairment}

The tubular and glomerular dysfunction among lithium users is reflected by loss of renal filtration capacity, which culminates in mild to severe impairment, and by functional loss with chronic kidney disease ${ }^{47}$. About $50 \%$ of patients taking lithium have decreased urinary concentration ${ }^{47}$. The mechanism involves four associated actions of lithium on the kidney in animal models: interference with the ability to generate cyclic adenosine monophosphate (AMP) in response to stimulation of antidiuretic hormone by the cortical portion of the collecting duct cells ${ }^{47}$; inhibition of adenosines triphosphatases ${ }^{48}$; suppression (downregulation) of the synthesis of aquaporins ${ }^{49}$; and interference with the production of prostaglandins ${ }^{50}$. The clinical result is the consequent thirst with polyuria reported by patients. Long-term studies reported approximately a $15 \%$ incidence of irreversible decrease in the urinary concentrating ability of lithium users ${ }^{51,52}$. This effect can be more frequently found with lithium administered twice daily as compared with a single administration of an extended release formulation ${ }^{53,54}$. A study using other markers of kidney damage, such as $\beta 2$-microglobulin (associated with proximal tubular injury) and glucosaminoglycan (component of the glomerular basement membrane) in 107 lithium users between 1 and 15 years with bipolar disorder were compared with 29 controls with other psychiatric disorders ${ }^{55}$. The 24 -hour urine volume and markers used in this study were high, while the osmolality was decreased in the group using lithium. The excretion of $\beta 2$-microglobulin was significantly higher in patients with polyuria as well as in those with greatest impairment of urinary concentrating ability. The duration of lithium treatment was not correlated with the change in urinary concentrating ability.

Tubular dysfunction may be more complex, represented by diabetes insipidus, defined by a 24 hours urine output above 3 liters with a hypotonic characteristic (urinary osmolality ratio by plasma smaller than 1) $)^{9,47}$. Normally, this change is usually reversible by treatment (duration of lithium treatment about six years), but turns into an irreversible damage after a long period of prescription (around 15 years or more). There are reports of a $27 \%$ incidence of diabetes insipidus in a short period of follow-up (4 months), significantly associated with the combined use of serotonergic antidepressants ${ }^{56}$. In a previous study, patients with bipolar disorder were evaluated for both renal and urinary concentrating ability dysfunction, being divided into three groups: 10 with no previous use of lithium, 10 with the use of short-term and 10 with long-term usage ${ }^{57}$. The creatinine clearance in patients with long-term regimen was significantly lower than that of the other two groups. After 8 hours of water deprivation and also after injection of desmopressin, there was no difference between groups in terms of urinary osmolality. However, when each patient was assessed individually in terms of their ability to concentrate kidney, there was partial diabetes insipidus in four patients in the long term and in two patients in short-term treatment.

In this context, tubular dysfunction can occur during the initial treatment with lithium, can be independent of serum lithium levels, and even start with diabetes insipidus. However, the detection of early signs of tubular impairment from simple urinary analysis exam (e.g. altered urinary density) can provide a fast and easy way to handle with this possible adverse effect and avoid an irreversible lesion or a severe dysfunction such as diabetes insipidus.

The glomerular involvement is the most important organic adverse event related to lithium treatment. This dysfunction and its magnitude remains much more controversial in terms of prevalence among lithium users if we evaluate the evidence presented in most clinical studies, especially because there are a few well-designed studies such as long-term randomized and placebo-controlled ${ }^{10,11,47}$. A review of 14 studies that were published before 1987 estimated a $15 \%$ prevalence for the reduction of glomerular filtration rate (GFR) (Button et al., 1987). Several studies between the 1980s and 1990s showed no significant change in GFR or just a slight functional deterioration with the use of lithium in the long-term follow-up ${ }^{43,58-63}$. However, five more recent studies reported that between 21 and $55 \%$ of patients treated with lithium presented a GFR of less than $60 \mathrm{ml} / \mathrm{min} / 1.73 \mathrm{~m}^{2}$, corresponding to the cutoff for the third stage of renal disease ${ }^{64-69}$. A recent systematic review selected 23 studies that investigated the effect of the use of lithium on renal function, dividing them into three categories: cross-sectional case-control studies, pre and post-lithium treatment studies, and observational long-term studies ${ }^{10}$. In all three categories, increased creatinine was observed in favor of lithium users, being significant and very mild only in the first and third category ${ }^{10}$. However, Bendz et al. ${ }^{70}$ in an observational study reported a $1.2 \%$ prevalence of renal failure and a 2.5 times higher risk for dialysis among lithium users, resulting in a 6 fold greater risk for the disease than the general population. This study also noted that even with the interruption of the drug, creatinine level continued to increase if its previous level was above $2.5 \mathrm{mg} / \mathrm{dL}$ when lithium was withdrawn ${ }^{70}$. In another epidemiological study with patients in dialysis across France, lithium was associated as a cause of renal failure in 2 among 1,000 subjects $^{51}$.

In a transversal study with 13 long-term lithium users (mean usage: 10 years; mean blood levels: $0.66 \mathrm{mmol} / \mathrm{L}$ ) and 13 controls were evaluated during the fifth and ninth week after lithium withdrawn ${ }^{44}$. Although there was no significant difference in GFR between the groups, there was an improvement in GFR among lithium users after the discontinuation. The maximum urinary concentrating ability 
did not show any improvement after drug withdrawn, remaining lower in the group of lithium users ${ }^{44}$. In a retrospective study of this cohort after 8-12 years of follow-up, it was observed that both the urinary concentrating ability and GFR were not lower when compared with those who died or who discontinued lithium ${ }^{65}$. Of this sample, one patient died attributed to severe renal impairment due to lithium. Urinary concentration ability and GFR were reevaluated in the remaining of this sample and were significantly declined when compared to baseline measures.

The exact time to develop glomerular dysfunction is not fully understood. In a retrospective study, $21 \%$ of the sample under lithium developed some degree of renal impairment ${ }^{66}$. Both the duration of treatment as well as the blood levels did not influence the development of renal failure. In a prospective study, renal function was assessed at the end of 11.5 years of follow-up ${ }^{71}$. Lithium users presented a lower GFR compared to controls, however the correlation between lithium exposure time and loss of renal function was not significant.

Taking all this evidence into account, lithium can be associated with a possible glomerular dysfunction usually after long-term treatment. However, end-stage renal impairment is not a common event. Monitoring renal function seems to be the best approach to avoid and manage this kind of adverse event, especially in patients with high risk of renal dysfunction such as those with hypertension and diabetes.

\section{Pregnancy and teratogenic risk}

Although there is evidence that lithium may be teratogenic, they are not solid. Six case-control studies $(n=264)$ evaluated the association of Ebstein's anomaly and use of lithium, finding no significant difference in incidence when comparing women exposed and not exposed to lithium ${ }^{72}$. In addition, a major study comparing 10,698 neonates with congenital abnormality 21,546 healthy neonates found no evidence of association of lithium with congenital anomalies ${ }^{73}$. The number of newborns exposed to lithium was small, both in affected cases (6 in 10,698) and in healthy controls (5 in 21,546 subjects).

Although one cannot rule out that lithium has a teratogenic potential, the current trend in the literature is to say that the risk has been overestimated at least. Therefore, one should avoid the use of lithium in the first trimester of pregnancy, but taking into account that the risk of teratogenesis may exist, but the prevalence is not as high as previously estimated.

If there is discovery of pregnancy in patients taking lithium and choose to discontinue the drug, discontinuation can be done gradually in 2-4 weeks as abrupt withdrawal is associated with increased risk of relapse ${ }^{74}$. It is recommended reintroducing lithium quickly after the baby's birth, as the postpartum period increases the risk of relapse $\mathrm{e}^{75}$.

\section{Additional laboratorial and imaging findings}

Some laboratorial findings can be early observed in patients with lithium, corresponding to biological effects of the drug even at low serum levels. Potential relevant changes in renal, thyroid and parathyroid function were addressed earlier in this review. It is quite commonly observed an increase in the leukocyte count secondary to a 1.5 times the upper limit of the neutrophil count in the complete blood work of a patient using lithium ${ }^{76}$. Changes in glucose metabolism has been described, including the development of diabetes mellitus ${ }^{77,78}$. Most controlled studies have indirectly associated lithium with glucose intolerance or even diabetes, being this effect attributed to the weight gain secondary to the medication use ${ }^{77,79}$. Lithium may reduce the serum prolactin levels, unlike most other psychotropics $^{80,81}$. Hypermagnesemia is also often associated with the use of lithium, reaching $30 \%$ of patients ${ }^{41}$.

Nonspecific changes of ventricular repolarization on the electrocardiogram, without clinical symptoms, were described with the concomitant use of lithium, totaling 13 to $100 \%$ of patients, depending on the study ${ }^{74}$. Epileptic activity can be observed during an electroencephalogram without clinical manifestations ${ }^{82}$. This non-convulsive epilepsy is usually associated with a higher blood levels, although it can be seen at normal serum concentrations and at overt seizures 83,84 .

In lithium users, there are also structural changes in the kidneys in addition to functional changes already described. Pathological findings in subjects treated with lithium show chronic tubulointerstitial nephropathy including tubular atrophy and interstitial fibrosis interspersed with tubular dilations and cysts ${ }^{85,86}$. The microcystic formations, usually multiple, are seen between 33 and $62.5 \%$ of patients on MRI scans, both in the cortex and in the medulla, especially in regions with extensive atrophy and fibrosis ${ }^{85,86}$. Normally, the involvement is bilateral and sparse, not exceeding $1-2 \mathrm{~mm}$ in diameter ${ }^{85,86}$. Cysts may exceed $3 \mathrm{~mm}$ and did not correlate with the presence of renal dysfunction ${ }^{87}$.

\section{Pharmacological interaction}

The main drugs that can interfere with the plasma concentrations of lithium, increasing them, are alprazolam ${ }^{8}$, thiazide diuretics, ACE inhibitors ${ }^{89}$ and anti-inflammatory non-steroidal drugs. Therefore, it is safe to reduce the amount of lithium in $40-50 \%$ before prescribing a diuretic, for example. Amiloride is preferable to others diuretics as it less likely affects lithium levels, given its ability to block lithium uptake at the epithelial sodium channel ${ }^{90}$. Drugs that lower lithium concentrations by increasing the clearance are theophylline, acetazolamide, mannitol and caffeine ${ }^{38}$.

It is important to note that the use of propranolol can decrease lithium clearance ${ }^{77}$. Caution is required when administering calcium channel antagonists and angiotensin II antagonists with lithium, since several reports on poisoning in combination of lithium have been described 78,79 . The use of xanthines (theophylline, caffeine) may increase $20-25 \%$ of the current lithium blood levels. The use of NSAIDs (excluding acetylsalicylic acid) requires reduction of about $20 \%$ of the administered dose of lithium ${ }^{83}$.

The safety of the use of lithium in patients receiving electroconvulsive therapy (ECT) is controversial. There are two studies that found an incidence of 5-10\% of delirium in patients who were using electroconvulsive therapy in combination with lithium ${ }^{82,91}$. Therefore, it is prudent to suspend or lower the dose of lithium among patients elected to electroconvulsive therapy.

\section{Conclusions}

Lithium is a standard treatment for bipolar disorder, also indicated in association with antidepressants for unipolar depression. Short-term lithium use has only mild side effects and that the most severe side effects (on target organs) are not common and can be prevented through periodical monitoring in subjects requiring chronic treatment.

The authors of the present manuscript report no conflict of interest in the conduction of this study.

\section{References}

1. Schou M, Juel-Nielsen N, Stromgren E, Voldby H. The treatment of manic psychoses by the administration of lithium salts. J Neurol Neurosurg Psychiatry. 1954;17(4):250-60.

2. Geddes JR, Burgess S, Hawton K, Jamison K, Goodwin GM. Long-term lithium therapy for bipolar disorder: systematic review and meta-analysis of randomized controlled trials. Am J Psychiatry. 2004;161(2):217-22.

3. Cipriani A, Pretty H, Hawton K, Geddes JR. Lithium in the prevention of suicidal behavior and all-cause mortality in patients with mood disorders: a systematic review of randomized trials. Am J Psychiatry. 2005;162(10):1805-19.

4. Ohgami H, Terao T, Shiotsuki I, Ishii N, Iwata N. Lithium levels in drinking water and risk of suicide. Br J Psychiatry. 2009;194(5):464-5; discussion 46.

5. Forlenza OV, Diniz BS, Radanovic M, Santos FS, Talib LL, Gattaz WF Disease-modifying properties of long-term lithium treatment for 
amnestic mild cognitive impairment: randomised controlled trial. Br J Psychiatry. 2011;198(5):351-6.

6. Aggarwal SP, Zinman L, Simpson E, McKinley J, Jackson KE, Pinto H, et al. Safety and efficacy of lithium in combination with riluzole for treatment of amyotrophic lateral sclerosis: a randomised, double-blind, placebo-controlled trial. Lancet Neurol. 2010;9(5):481-8.

7. Yang ML, Li JJ, So KF, Chen JY, Cheng WS, Wu J, et al. Efficacy and safety of lithium carbonate treatment of chronic spinal cord injuries: a double-blind, randomized, placebo-controlled clinical trial. Spinal Cord. 2012;50(2):141-6.

8. Young AH, Hammond JM. Lithium in mood disorders: increasing evidence base, declining use? Br J Psychiatry. 2007;191:474-6.

9. Grandjean EM, Aubry JM. Lithium: updated human knowledge using an evidence-based approach: part III: clinical safety. CNS Drugs. 2009;23(5):397-418.

10. Paul R, Minay J, Cardwell C, Fogarty D, Kelly C. Meta-analysis of the effects of lithium usage on serum creatinine levels. J Psychopharmacol. 2010;24(10):1425-31.

11. McKnight RF, Adida M, Budge K, Stockton S, Goodwin GM, Geddes JR. Lithium toxicity profile: a systematic review and meta-analysis. Lancet. 2012;379(9817):721-8.

12. Mellerup ET, Plenge P. The side effects of lithium. Biol Psychiatry. 1990;28(6):464-6.

13. Rybakowski J, Suwalska A. Gastrointestinal metabolic and body-weight changes during treatment with lithium. UK; 2006.

14. Using lithium safely. Drug Ther Bull. 1999;37(3):22-4.

15. Kleindienst N, Greil W. Inter-episodic morbidity and drop-out under carbamazepine and lithium in the maintenance treatment of bipolar disorder. Psychol Med. 2002;32(3):493-501.

16. Calabrese JR, Shelton MD, Rapport DJ, et al. A 20-month, double-blind, maintenance trial of lithium versus divalproex in rapid-cycling bipolar disorder. Am J Psychiatry. 2005;162(11):2152-61.

17. Schou M. The combat of non-compliance during prophylactic lithium treatment. Acta Psychiatr Scand. 1997;95(5):361-3.

18. Vasile RG, Shelton RP. Alleviating gastrointestinal side effects of lithium carbonate by substituting lithium citrate. J Clin Psychopharmacol. 1982;2(6):420-3.

19. KeckPE. Long-term therapy of bipolar illness. JFam Pract. 2003;Suppl:S18-21.

20. Ahmad M, Elnakady Y, Farooq M, Wadaan M. Lithium induced toxicity in rats: blood serum chemistry, antioxidative enzymes in red blood cells and histopathological studies. Biol Pharm Bull. 2011;34(2):272-7.

21. Sharma SD, Iqbal M. Lithium induced toxicity in rats: a hematological, biochemical and histopathological study. Biol Pharm Bull. 2005;28(5):834-7.

22. Pogarell O, Folkerts $M$, Hegerl U. Adverse neurological and neurotoxic effects of lithium therapy. UK; 2006.

23. Honig A, Arts BM, Ponds RW, Riedel WJ. Lithium induced cognitive side-effects in bipolar disorder: a qualitative analysis and implications for daily practice. Int Clin Psychopharmacol. 1999;14(3):167-71.

24. Stip E, Dufresne J, Lussier I, Yatham L. A double-blind, placebo-controlled study of the effects of lithium on cognition in healthy subjects: mild and selective effects on learning. J Affect Disord. 2000;60(3):147-57.

25. Pachet AK, Wisniewski AM. The effects of lithium on cognition: an updated review. Psychopharmacology (Berl). 2003;170(3):225-34.

26. Bell EC, Willson MC, Wilman AH, Dave S, Asghar SJ, Silverstone PH. Lithium and valproate attenuate dextroamphetamine-induced changes in brain activation. Hum Psychopharmacol. 2005;20(2):87-96.

27. Baptista T, Alastre T, Contreras Q, Martinez JL, Araujo de Baptista E, Burguera JL, et al. Effects of lithium carbonate on reproductive hormones in healthy men: relationship with body weight regulation--a pilot study. Prog Neuropsychopharmacol Biol Psychiatry. 1997;21(6):937-50.

28. Baptista T, Lacruz A, de Mendoza S, Guillén MM, Burguera JL, de Burguera $\mathrm{M}$, et al. Endocrine effects of lithium carbonate in healthy premenopausal women: relationship with body weight regulation. Prog Neuropsychopharmacol Biol Psychiatry. 2000;24(1):1-16.

29. Livingstone $C$, Rampes $H$. Lithium: a review of its metabolic adverse effects. J Psychopharmacol. 2006;20(3):347-55.

30. Berens SC, Bernstein RS, Robbins J, Wolff J. Antithyroid effects of lithium. J Clin Invest. 1970;49(7):1357-67.

31. Burrow GN, Burke WR, Himmelhoch JM, Spencer RP, Hershman JM. Effect of lithium on thyroid function. J Clin Endocrinol Metab. 1971;32(5):647-52.
32. Lazarus JH. The effects of lithium therapy on thyroid and thyrotropin-releasing hormone. Thyroid. 1998;8(10):909-13.

33. Kleiner J, Altshuler L, Hendrick V, Hershman JM. Lithium-induced subclinical hypothyroidism: review of the literature and guidelines for treatment. J Clin Psychiatry. 1999;60(4):249-55.

34. Lazarus JH. Lithium and thyroid. Best Pract Res Clin Endocrinol Metab. 2009;23(6):723-33.

35. Kusalic M, Engelsmann F. Effect of lithium maintenance therapy on thyroid and parathyroid function. J Psychiatry Neurosci. 1999;24(3):22733.

36. Johnston AM, Eagles JM. Lithium-associated clinical hypothyroidism. Prevalence and risk factors. Br J Psychiatry. 1999;175:336-9.

37. Frye MA, Denicoff KD, Bryan AL, Smith-Jackson EE, Ali SO, Luckenbaugh D, et al. Association between lower serum free T4 and greater mood instability and depression in lithium-maintained bipolar patients. Am J Psychiatry. 1999;156(12):1909-14.

38. Bocchetta A, Bernardi F, Pedditzi M, Loviselli A, Velluzzi F, Martino E, et al. Thyroid abnormalities during lithium treatment. Acta Psychiatr Scand. 1991;83(3):193-8.

39. Barclay ML, Brownlie BE, Turner JG, Wells JE. Lithium associated thyrotoxicosis: a report of 14 cases, with statistical analysis of incidence. Clin Endocrinol (Oxf). 1994;40(6):759-64.

40. Miller KK, Daniels GH. Association between lithium use and thyrotoxicosis caused by silent thyroiditis. Clin Endocrinol (Oxf). 2001;55(4):501-8.

41. Groleau G. Lithium toxicity. Emerg Med Clin North Am. 1994;12(2):51131.

42. Szalat A, Mazeh H, Freund HR. Lithium-associated hyperparathyroidism: report of four cases and review of the literature. Eur J Endocrinol. 2009;160(2):317-23.

43. Kallner G, Petterson U. Renal, thyroid and parathyroid function during lithium treatment: laboratory tests in 207 people treated for 1-30 years. Acta Psychiatr Scand. 1995;91(1):48-51.

44. Bendz H, Sjödin I, Toss G, Berglund K. Hyperparathyroidism and long-term lithium therapy--a cross-sectional study and the effect of lithium withdrawal. J Intern Med. 1996;240(6):357-65.

45. Mak TW, Shek CC, Chow CC, Wing YK, Lee S. Effects of lithium therapy on bone mineral metabolism: a two-year prospective longitudinal study. J Clin Endocrinol Metab. 1998;83(11):3857-9.

46. NICE guideline. Bipolar disorder: the management of bipolar disorder in adults, children and adolescents, in primary and secondary care: quick reference guide; 2006.

47. Grünfeld JP, Rossier BC. Lithium nephrotoxicity revisited. Nat Rev Nephrol. 2009;5(5):270-6.

48. Eiam-Ong S, Dafnis E, Spohn M, Kurtzman NA, Sabatini S. H-K-ATPase in distal renal tubular acidosis: urinary tract obstruction, lithium, and amiloride. Am J Physiol. 1993;265(6 Pt 2):F875-80.

49. Marples D, Christensen S, Christensen EI, Ottosen PD, Nielsen S. Lithium-induced downregulation of aquaporin-2 water channel expression in rat kidney medulla. J Clin Invest. 1995;95(4):1838-45.

50. Kotnik P, Nielsen J, Kwon TH, Krzisnik C, Frøkiaer J, Nielsen S. Altered expression of COX-1, COX-2, and mPGES in rats with nephrogenic and central diabetes insipidus. Am J Physiol Renal Physiol. 2005;288(5):F1053-68

51. Presne C, Fakhouri F, Noël LH, Stengel B, Even C, Kreis H, et al. Lithium-induced nephropathy: Rate of progression and prognostic factors. Kidney Int. 2003;64(2):585-92.

52. Schou M, Kampf D. Lithium and the kidneys. UK; 2006

53. Kusalic M, Engelsmann F. Renal reactions to changes of lithium dosage. Neuropsychobiology. 1996;34(3):113-6.

54. Singh LK, Nizamie SH, Akhtar S, Praharaj SK. Improving tolerability of lithium with a once-daily dosing schedule. Am J Ther. 2011;18(4):288-91.

55. Coşkunol H, Vahip S, Mees ED, Başçi A, Bayindir O, Tuğlulaŕ I. Renal side-effects of long-term lithium treatment. J Affect Disord. 1997;43(1):510 .

56. Movig KL, Baumgarten R, Leufkens HG, van Laarhoven JH, Egberts AC. Risk factors for the development of lithium-induced polyuria. Br J Psychiatry. 2003;182:319-23.

57. Turan T, Eşel E, Tokgöz B, Aslan S, Sofuoğlu S, Utaş C, et al. Effects of short- and long-term lithium treatment on kidney functioning in patients with bipolar mood disorder. Prog Neuropsychopharmacol Biol Psychiatry. 2002;26(3):561-5. 
58. Johnson G. Lithium. Med J Aust. 1984;141(9):595-601.

59. Jensen SB, Rickers H. Glomerular filtration rate during lithium therapy. A longitudinal study. Acta Psychiatr Scand. 1984;70(3):235-8.

60. Løkkegaard H, Andersen NF, Henriksen E, Bartels PD, Brahm M, Baastrup PC, et al. Renal function in 153 manic-depressive patients treated with lithium for more than five years. Acta Psychiatr Scand. 1985;71(4):347-55.

61. Waller DG, Edwards JG, Papasthatis-Papayanni S. A longitudinal assessment of renal function during treatment with lithium. Q J Med. 1988;68(255):553-8.

62. Schou M. Serum lithium monitoring of prophylactic treatment. Critical review and updated recommendations. Clin Pharmacokinet. 1988;15(5):283-6.

63. Povlsen UJ, Hetmar O, Ladefoged J, Bolwig TG. Kidney functioning during lithium treatment: a prospective study of patients treated with lithium for up to ten years. Acta Psychiatr Scand. 1992;85(1):56-60.

64. Bendz H, Aurell M, Balldin J, Mathé AA, Sjödin I. Kidney damage in long-term lithium patients: a cross-sectional study of patients with 15 years or more on lithium. Nephrol Dial Transplant. 1994;9(9):1250-4.

65. Bendz H, Aurell M, Lanke J. A historical cohort study of kidney damage in long-term lithium patients: continued surveillance needed. Eur Psychiatry. 2001;16(4):199-206.

66. Lepkifker E, Sverdlik A, Iancu I, Ziv R, Segev S, Kotler M. Renal insufficiency in long-term lithium treatment. J Clin Psychiatry. 2004;65(6):850-6.

67. Bassilios N, Martel P, Godard V, Froissart M, Grünfeld JP, Stengel B, et al. Monitoring of glomerular filtration rate in lithium-treated outpatients--an ambulatory laboratory database surveillance. Nephrol Dial Transplant. 2008;23(2):562-5.

68. McCann SM, Daly J, Kelly CB. The impact of long-term lithium treatment on renal function in an outpatient population. Ulster Med J. 2008;77(2):102-5.

69. Janowsky DS, Soares J, Hatch JP, Zunta-Soares G, Hu Q, Davis JM. Lithium effect on renal glomerular function in individuals with intellectual disability. J Clin Psychopharmacol. 2009;29(3):296-9.

70. Bendz H, Schön S, Attman PO, Aurell M. Renal failure occurs in chronic lithium treatment but is uncommon. Kidney Int. 2010;77(3):219-24.

71. Tredget J, Kirov A, Kirov G. Effects of chronic lithium treatment on renal function. J Affect Disord. 2010;126(3):436-40.

72. Sadoul JL, Kezachian B, Freychet P. [Lithium therapy and hyperthyroidism: disease caused or facilitated by lithium? Review of the literature apropos of a case of hyperthyroidism preceded by transient hypothyroidism]. Ann Endocrinol (Paris). 1994;54(5):353-8.

73. Massey EW, Folger WN. Seizures activated by therapeutic levels of lithium carbonate. South Med J. 1984;77(9):1173-5.

74. Bierbrauer J, Albrecht J, Müller-Oerlinghausen B. Lithium and its cardiovascular effects. UK; 2006.

75. Kusalic M, Engelsmann F. Effect of lithium maintenance treatment on hypothalamic pituitary gonadal axis in bipolar men. J Psychiatry Neurosci. 1996;21(3):181-6.
76. Inayat $\mathrm{M}$, Gallicchio V. The effects of lithium on the immune system. UK; 2006.

77. Vendsborg PB, Bach-Mortensen N, Rafaelsen OJ. Fat cell number and weight gain in lithium treated patients. Acta Psychiatr Scand. 1976;53(5):355-9.

78. Kuruvilla PK, Alexander J. Lithium toxicity presenting as non-convulsive status epilepticus (NCSE). Aust N Z J Psychiatry. 2001;35(6):852.

79. Vestergaard P, Schou M. Does long-term lithium treatment induce diabetes mellitus? Neuropsychobiology. 1987;17(3):130-2.

80. Baştürk M, Karaaslan F, Esel E, Sofuoğlu S, Tutuş A, Yabanoğlu I. Effects of short and long-term lithium treatment on serum prolactin levels in patients with bipolar affective disorder. Prog Neuropsychopharmacol Biol Psychiatry. 2001;25(2):315-22.

81. El Khoury A, Tham A, Mathé AA, Aberg-Wistedt A, Stain-Malmgren R. Decreased plasma prolactin release in euthymic lithium-treated women with bipolar disorder. Neuropsychobiology. 2003;48(1):14-8.

82. Bellesi M, Passamonti L, Silvestrini M, Bartolini M, Provinciali L. Non-convulsive status epilepticus during lithium treatment at therapeutic doses. Neurol Sci. 2006;26(6):444-6.

83. Yip KK, Yeung WT. Lithium overdose causing non-convulsive status epilepticus--the importance of lithium levels and the electroencephalography in diagnosis. Hong Kong Med J. 2007;13(6):471-4.

84. Gansaeuer M, Alsaadi TM. Lithium intoxication mimicking clinical and electrographic features of status epilepticus: a case report and review of the literature. Clin Electroencephalogr. 2003;34(1):28-31.

85. Farres MT, Ronco P, Saadoun D, Remy P, Vincent F, Khalil A, et al Chronic lithium nephropathy: MR imaging for diagnosis. Radiology. 2003;229(2):570-4.

86. Tuazon J, Casalino D, Syed E, Batlle D. Lithium-associated kidney microcysts. ScientificWorldJournal. 2008;8:828-9.

87. Roque A, Herédia V, Ramalho M, de Campos R, Ferreira A, Azevedo $\mathrm{R}$, et al. MR findings of lithium-related kidney disease: preliminary observations in four patients. Abdom Imaging. 2012;37(1):140-6.

88. Baethge C, Blumentritt $\mathrm{H}$, Berghöfer A, Bschor T, Glenn T, Adli M, et al. Long-term lithium treatment and thyroid antibodies: a controlled study. J Psychiatry Neurosci. 2005;30(6):423-7.

89. Diebold K, Michel G, Schweizer J, Diebold-Dörsam M, Fiehn W, Kohl B Are psychoactive-drug-induced changes in plasma lipid and lipoprotein levels of significance for clinical remission in psychiatric disorders? Pharmacopsychiatry. 1998;31(2):60-7.

90. Kortenoeven ML, Li Y, Shaw S, Gaeggeler HP, Rossier BC, Wetzels JF, et al. Amiloride blocks lithium entry through the sodium channel thereby attenuating the resultant nephrogenic diabetes insipidus. Kidney Int 2009;76(1):44-53.

91. Kaplan PW, Birbeck G. Lithium-induced confusional states: nonconvulsive status epilepticus or triphasic encephalopathy? Epilepsia. 2006;47(12):2071-4. 